\title{
MICROBIOLOGICAL PROFILE OF EAR DISCHARGE IN CHRONIC SUPPURATIVE OTITIS MEDIA
}

\author{
Bibhuti Das ${ }^{1}$, Surajeet Basumatari ${ }^{2}$
}

${ }^{1}$ Registrar, Department of ENT, FAAMCH, Barpeta, Assam.

${ }^{2}$ Associate Professor, Department of ENT, FAAMCH, Barpeta, Assam.

\begin{abstract}
\section{BACKGROUND}

Chronic suppurative otitis media (CSOM) is defined as the inflammation of the mucous membrane of the middle ear cleft which includes the middle ear cavity, mastoid antrum, the mastoid air cells and the Eustachian tube. Complex interactions between the environment, microbes, and host are thought to lead to the development of this multifactorial disease. Understanding of the microbiology of chronic otitis media is important for efficient and effective treatment, and prevention of complications and antibiotic resistance. Thus, the study was conducted with the aim to determine the bacteriological agents implicated in discharging ears of the patients of CSOM and to determine the associated clinco-epidemiological factors among the patients of CSOM.
\end{abstract}

\section{MATERIALS AND METHODS}

This hospital-based descriptive study was conducted in 100 patients attending the ENT OPD in Fakhruddin Ali Ahmed Medical College, Barpeta, Assam from July 2016 to June 2017. Detailed clinical history and demographic data were collected and analysed. Ear discharge was collected and microbiological profile was evaluated.

\section{RESULTS}

One hundred patients after fulfilling the inclusion and exclusion criteria were chosen for the study. 31-40 years age group was most commonly involved with male preponderance. Microbiological analysis of ear discharge showed that Gram-negative bacteria accounted for $76 \%$ and Gram-positive bacteria were found in 34\% cases. Gram-negative bacteria included Pseudomonas aeruginosa 24\%, Klebsiella spp. 19\%, Proteus spp. 12\% and Escherichia coli 10\%. The Gram-positive aerobes identified included Staphylococcus spp. 15\%. The most common anaerobes identified were Bacteroides spp. in 1\%, Peptostreptococcus spp. in 1\% cases. Fungal growth was seen in $5 \%$ cases. Diphtheroids were seen in $3 \%$ cases.

\section{CONCLUSION}

Continuous and periodic evaluation of microbiological pattern and antibiotic sensitivity of isolates is necessary to decrease the potential risk of complications by early institution of appropriate treatment. Our study emphasised the need of proper identification of microbiological profile of the cases of CSOM in order to facilitate early institution of proper treatment.

\section{KEYWORDS}

Chronic Suppurative Otitis Media, Bacterial Isolates.

HOW TO CITE THIS ARTICLE: Das B, Basumatari S. Microbiological profile of ear discharge in chronic suppurative otitis media. J. Evolution Med. Dent. Sci. 2017;6(71):5040-5044, DOI: 10.14260/Jemds/2017/1096

\section{BACKGROUND}

Chronic suppurative otitis media (CSOM) is defined as a perforation of the tympanic membrane, with persistent drainage of pus from the middle ear, lasting at least six weeks. ${ }^{1}$ It is the inflammation of the mucous membrane of the middle ear cleft which includes the middle ear cavity, mastoid antrum, the mastoid air cells and the Eustachian tube. ${ }^{2}$ The global burden of illness from CSOM is estimated to involve about 65 to 330 million individuals with draining ears, $60 \%$ (39 to 200 million) of whom suffer from significant hearing impairment. ${ }^{3}$ Over $90 \%$ of the burden is borne by developing countries in Southeast Asia, the Western Pacific Region, and Africa. ${ }^{3}$

Financial or Other, Competing Interest: None.

Submission 28-07-2017, Peer Review 21-08-2017,

Acceptance 28-08-2017, Published 04-09-2017.

Corresponding Author:

Dr. Bibhuti Das,

C/o. Amiya Kumar Das,

House No. 143, Saurav Nagar,

Beltola, Guwahati-781028,

Dist. Kamrup Metro, Assam.

E-mail: drbibhutidas9@gmail.com

DOI: $10.14260 /$ jemds/2017/1096
CSOM often begins as an acute infection of the middle ear, acute otitis media (AOM), which occurs in up to $80 \%$ of children by the age of $3.4,5$ While most cases resolve spontaneously, a small minority of patients progress to a chronic phase characterised by chronic purulent ear discharge through a perforated tympanic membrane with associated inflammation of the mastoid and middle ear mucosa and hearing loss. CSOM can occur with or without cholesteatoma (epithelial inclusion cyst).

The pathogenesis of CSOM remains poorly understood. Complex interactions between the environment, microbes, and host are thought to lead to the development of this multifactorial disease. $5,6,7$

It has previously been assumed that a healthy individual's ear is sterile.8,9 Infections in the middle ear are thought to occur when pathogens enter the middle ear through the external ear canal or Eustachian tube. Bacteria have remained the most important aetiological agents in suppurative or discharging otitis media. Studies on microbiologic diagnoses of CSOM differ in regard to patient age, geography, and the presence of complications such as cholesteatomas, and these inconsistencies likely impact some of the variation in reported pathogens. Other theories to explain the persistent nature of this disease and repeated infection include toxin production by P. Aeruginosa, 10 
microbes embedding within the dead/damaged tissue (Cholesteatoma), ${ }^{11,12}$ formation of biofilms, ${ }^{13,14}$ recurrent bacterial infection from the nasopharynx not covered by the antibiotics prescribed, 15 or development of antibiotic resistance. ${ }^{16,17}$

Understanding of the microbiology of chronic otitis media is important for efficient and effective treatment, and prevention of complications and antibiotic resistance. In view of these, it is important to document the trend, to aid in appropriate treatment of this condition and help prevent its complications which may arise if otitis media is not treated or is improperly treated. This paper, therefore, aims to determine the bacteriological agents implicated in discharging ears of the patients of CSOM and to determine the associated clinco-epidemiological factors among CSOM patients attending the ENT OPD in Fakhruddin Ali Ahmed Medical College, Barpeta, Assam.

\section{MATERIALS AND METHODS}

This hospital-based descriptive study was conducted in the patients attending the ENT OPD in Fakhruddin Ali Ahmed Medical College, Barpeta, Assam from July 2016 to June 2017. Following are the criteria of choosing the patients for the study.

\section{Inclusion Criteria}

All patients with actively draining CSOM irrespective of nature, amount, odour after getting proper consent were included.

\section{Exclusion Criteria}

1. Patients with history of foreign body ear and/or infection of external auditory canal.

2. Patients on antibiotic or antifungal treatment (Ear drops or systemic) within the previous two weeks.

3. Patients with draining ears of less than two weeks duration.

All the 100 cases of actively draining CSOM attending the ENT OPD in Fakhruddin Ali Ahmed Medical College, Barpeta, Assam from July 2016 to June 2017 after fulfilling the inclusion and exclusion criteria were included in the study.

A detailed clinical history including age, gender, duration of discharge and antibiotic therapy was taken for all included patients. Patients of any age, both genders, unilateral or bilateral draining ears, resulting from CSOM of more than two weeks, were included in the study. Demographic data together with the patient's medical history and physical examination findings were noted down.

\section{Sampling method}

The study comprised of collection of discharge specimens from draining ears on the first day of contact with the patient. The ears were inspected first; discharge from the outer part of the ear canal was then cleaned by suction. A sterile swab stick was then introduced through a sterile aural speculum placed in the external auditory canal, and each specimen was collected from the bony part of the ear canal (Inner twothirds) or the middle ear cavity. Discharge specimens were collected from both ears for patients with bilateral draining. Each collected specimen was immediately placed in an anaerobic jar, under aseptic conditions, and transported, within one hour of collection, to the microbiology laboratory for routine microbiological culture and identification.
For bacterial isolation, the specimens were inoculated on blood agar, MacConkey's agar, chocolate agar and Robertson's cooked meat medium for aerobic and anaerobic cultures. For anaerobic bacteria, anaerobic blood agars were incubated in an anaerobic jar to permit recovery of anaerobic pathogens. For fungi isolation, a part of the pus specimen was cultured on Sabouraud's dextrose agar. The culture plates were incubated at $37^{\circ} \mathrm{C}$ for 24 to 48 hours. Anaerobic culture plates were incubated for seven days to allow growth of anaerobes, which grow slowly compared to aerobes. The isolates from the culture plates were identified using Gram staining, colony morphology, catalase, coagulase, oxidase, and biochemical strips. For fungal growth, Lactophenol cotton blue was used for final identification, and culture was for no less than seven days.

\section{Statistical Analysis}

Data were analysed statistically in GraphPad Software 2017 Inc version. Age of the patients were arranged with mean age with standard deviation.

\section{RESULTS}

This study was conducted in the Department of ENT, FAAMCH, Barpeta for a duration of six months from January 2017 to June 2017 on 138 patients after fulfilling the inclusion and exclusion criteria. However, only 100 patients cooperated in the study with subsequent followup with investigation reports. Hence, 100 patients were chosen for the study. All the findings were documented and summarised as follows.

\begin{tabular}{|c|c|c|}
\hline Age in Years & No. of Patients & \% of Patients \\
\hline$<10$ & 8 & 8 \\
\hline $11-20$ & 18 & 18 \\
\hline $21-30$ & 15 & 15 \\
\hline $31-40$ & 27 & 27 \\
\hline $41-50$ & 19 & 19 \\
\hline$>51$ & 13 & 13 \\
\hline \multicolumn{2}{|c|}{ Table 1. Age Distribution } \\
\hline
\end{tabular}

31-40 years age group was most commonly involved with $27 \%$ cases followed by 41-50 years, 21-30 years, $11-20$ years, 51 years and above and less than 10 years.

\begin{tabular}{|c|c|c|}
\hline Gender & No. of Cases & \% of Cases \\
\hline Male & 64 & 64 \\
\hline Female & 46 & 46 \\
\hline \multicolumn{2}{|c|}{ Table 2. Gender Distribution } \\
\hline
\end{tabular}

$64 \%$ cases were male while $46 \%$ cases were female. Male to female ratio was $1.39: 1$ which indicates male preponderance over female.

\begin{tabular}{|c|c|}
\hline Socioeconomic Status & \% of cases \\
\hline Class I (>Rs. 5522) & 7 \\
\hline Class II (Rs. 2761 - Rs. 5521) & 12 \\
\hline Class III (Rs. 1657- Rs. 2760) & 33 \\
\hline Class IV (Rs. 828-Rs. 1656) & 38 \\
\hline \multicolumn{2}{|c|}{ Class V (<Rs. 828) } \\
\hline \multicolumn{2}{|c|}{ Table 3. Socioeconomic Distribution } \\
\hline
\end{tabular}

According to Modified B.G. Prasad Socioeconomic classification, study population was divided into five classes. 
Class IV was most frequently involved followed by class III, class II, class V and class I.

\begin{tabular}{|c|c|}
\hline Clinical Presentation & \% of Cases \\
\hline Ear discharge only & 41 \\
\hline Hearing loss only & 14 \\
\hline Ear discharge and hearing loss & 22 \\
\hline $\begin{array}{c}\text { Ear discharge + hearing loss+ earache } \\
\text { and/or tinnitus }\end{array}$ & 13 \\
\hline Ear discharge and complications & 10 \\
\hline Table 4. Distribution of Clinical Presentation \\
\hline
\end{tabular}

In this study, otorrhoea was the most common presenting symptom. This was followed by otorrhoea with hearing loss, hearing loss only \& otorrhoea with hearing loss with tinnitus \& earache \& complications.

\begin{tabular}{|c|c|}
\hline Clinical Features & \% of Cases \\
\hline Deviated nasal septum & 24 \\
\hline Pharyngotonsillitis & 14 \\
\hline Sinusitis & 11 \\
\hline Aural polyp & 12 \\
\hline Adenoid hypertrophy & 5 \\
\hline Table 5. Distribution of Associated Clinical Features \\
\hline
\end{tabular}

Besides clinical presentations of CSOM, all the cases were evaluated for associated clinical features. It was observed that $24 \%$ cases had Deviated nasal septum, 14\% had Pharyngotonsillitis, $11 \%$ had sinusitis, $12 \%$ cases had aural polyp and 5\% cases had adenoid hypertrophy.

\begin{tabular}{|c|c|}
\hline Characteristics Features & No. of Cases \\
\hline Discharge Type & 41 \\
Purulent & 28 \\
Mucopurulent & 15 \\
Mucoid & 16 \\
Blood stained & 63 \\
\hline Amount & 37 \\
Profuse \\
Scanty & 32 \\
Odour & 68 \\
\hline Foul smell+ & \\
Foul smell- & Table 6. Characteristics of Ear Discharge \\
\hline
\end{tabular}

In our study, $41 \%$ cases had purulent discharge, followed by mucopurulent (28\%), mucoid $(16 \%)$ and blood-stained discharge (12\%). 63\% cases had profuse otorrhoea while $37 \%$ cases had scanty ear discharge. $32 \%$ cases had foul smelling discharge.

\begin{tabular}{|c|c|}
\hline Type of Perforation/Retraction & No. of Cases \\
\hline Small perforation $(<25 \%)$ & 13 \\
\hline Medium $(25-50 \%)$ & 19 \\
\hline Large $(50 \%-75 \%)$ & 16 \\
\hline Subtotal $(>75 \%)$ & 14 \\
\hline Total & $\mathbf{1 1}$ \\
\hline Marginal & 9 \\
\hline Attic & 8 \\
\hline Retraction pocket & 8 \\
\hline Table 7. Distribution of Type of Tympanic Membrane \\
Perforation/Retraction \\
\hline
\end{tabular}

In our study, it was observed that medium perforation of tympanic membrane was seen in $19 \%$ cases. $16 \%, 14 \%$,
$13 \%$ \& $11 \%$ cases had subtotal, large, total small $\mathrm{TM}$ perforation respectively. Attic perforation, marginal perforation, Retraction pocket was seen in $10 \%, 9 \%$ \& $8 \%$ respectively.

\begin{tabular}{|c|c|}
\hline Bacterial Organisms & Frequency (\%) \\
\hline Pseudomonas aeruginosa & 24 \\
\hline Klebsiella spp. & 19 \\
\hline Staphylococcus spp. & 15 \\
\hline Proteus spp. & 12 \\
\hline Streptococcus spp. & 10 \\
\hline Escherichia coli & 10 \\
\hline Fungal & 5 \\
\hline Diphtheroids & 3 \\
\hline Bacteroides spp. & 1 \\
\hline Peptostreptococcus & 1 \\
\hline Table 8. Distribution of Bacteriology in Ear Discharge \\
\hline
\end{tabular}

On Gram staining, Gram-negative bacteria accounted for $76 \%$ and Gram-positive bacteria were found in 34\%. Bacteriological observation was categorised into aerobes and anaerobes. The most common aerobes identified from the specimens were Gram-negative bacteria, which included Pseudomonas aeruginosa 24\%, Klebsiella spp. 19\%, Proteus spp. $12 \%$ and Escherichia coli 10\%. The Gram-positive aerobes identified included Staphylococcus spp. 15\%. Anaerobes were also isolated from the specimens. The most common anaerobes identified were Bacteroides spp. in 1\%, Peptostreptococcus spp. in $1 \%$ cases. Fungal growth was seen in $5 \%$ cases. Diphtheroids were seen in 3\% cases.

\section{DISCUSSION}

CSOM is a major public-health problem, and India is one of the countries with high-prevalence where urgent attention is needed. It is a persistent disease with great risk of irreversible complications. CSOM is an important cause of preventable hearing loss particularly in the developing world 18 and a reason of serious concern, particularly in children, because it may have long-term effects on early communication, language development, auditory processing, educational process, and physiological and cognitive development which in turn has substantial economic burden on the health care system. Poor living conditions, overcrowding, poor hygiene and nutrition have been suggested as a basis for the widespread prevalence of CSOM in developing countries.

In our study, we found that 31-40 years age group was most commonly involved with $27 \%$ cases followed by $41-50$ years, 21-30 years, 11-20 years, 51 years and above and less than 10 years. The mean age was $33.6 \pm 12.93$ years.

Our study also found that $64 \%$ cases were male while $46 \%$ cases were female. Male to female ratio was 1.39:1 which indicates male preponderance over female. Chirwa et $\mathrm{al}^{19}$ in their study found that males were more affected than females, and this was similar to findings reported from the Ethiopian study by Melaku et al. ${ }^{20}$

In this study, otorrhoea (41\%) was the most common presenting symptom. This was followed by otorrhoea with hearing loss, hearing loss only \& otorrhoea with hearing loss with tinnitus and earache and complications. Van Hasselt P et $\mathrm{al}^{21}$ also found that otorrhoea was also the most common presenting symptom. 
Besides clinical presentations of CSOM, all the cases were evaluated for associated clinical features. It was observed that $24 \%$ cases had deviated nasal septum, $14 \%$ had Pharyngotonsillitis, $11 \%$ had sinusitis, $12 \%$ cases had aural polyp and $5 \%$ cases had adenoid hypertrophy.

In our study, $41 \%$ cases had purulent discharge, followed by mucopurulent (28\%), mucoid (16\%) and blood-stained discharge (12\%). 63\% cases had profuse otorrhoea while $37 \%$ cases had scanty ear discharge. $32 \%$ cases had foul smelling discharge. in the study by Chirwa et al, ${ }^{19}$ the pus drainage was mainly purulent and foul smelling in $76.2 \%$ and mucopurulent and odourless in $23.8 \%$. This was similar to a study in Bangladesh, where aural drainage was mucoid or mucopurulent in $80 \%$ of patients with tubotympanic CSOM and foul smelling, scanty ear drainage was present in $88 \%$ of patients with atticoantral CSOM. ${ }^{22}$

In our study, it was observed that medium perforation of tympanic membrane was seen in $19 \%$ cases. $16 \%, 14 \%, 13 \%$ \& $11 \%$ cases had subtotal, large, total small TM perforation respectively. Attic perforation, marginal perforation, Retraction pocket was seen in $10 \%, 9 \%$ \& $8 \%$ respectively.

On Gram staining, Gram-negative bacteria accounted for $76 \%$ and Gram-positive bacteria were found in 34\%. Bacteriological observation was categorised into aerobes and anaerobes. The most common aerobes identified from the specimens were Gram-negative bacteria, which included Pseudomonas aeruginosa 24\%, Klebsiella spp. 19\%, Proteus spp. $12 \%$ and Escherichia coli 10\%. The Gram-positive aerobes identified included Staphylococcus spp. 15\%. Anaerobes were also isolated from of the specimens. The most common anaerobes identified were Bacteroides spp. in $1 \%$, Peptostreptococcus spp. in $1 \%$ cases. Fungal growth was seen in $5 \%$ cases. Diphtheroids were seen in 3\% cases.

OA Afolabi et $\mathrm{al}^{23}$ studied the pattern of bacterial isolates which showed that Pseudomonas aeruginosa was the most prevalent bacterial organism found in the middle ear of the respondents with chronic suppurative otitis media which is similar to findings elsewhere $24,25,26$ and is followed by Klebsiella spp. as the second commonest. Kumar $\mathrm{H}$ et $\mathrm{al}^{27}$, Shymla $\mathrm{R}$ et $\mathrm{al}^{28}$ Osazuwa $\mathrm{F}$ et $\mathrm{al}^{29}$ and Mansoor $\mathrm{T}$ et $\mathrm{al}^{30}$ found Pseudomonas as the most prevalent organism in the isolates from the ear of the patients of CSOM.

Prakash et $\mathrm{al}^{31}$ in their study isolated Coliforms including Klebsiella pneumoniae and Escherichia coli from $9.42 \%$ and $7.33 \%$ cases respectively, and these findings were similar to the reports by Mansoor et $\mathrm{al}^{30}$ who reported the same to be $8 \%$ and $4 \%$ whereas Poorey and lyer et $\mathrm{al}^{32}$ reported a highincidence for Klebsiella in their study (25.4\%). A recent study by Shyamala and Reddy et al ${ }^{28}$ showed a little different trend where E. coli was reported in $12 \%$ and Klebsiella in $5 \%$ of cases. More frequent isolation of faecal bacteria like E. coli, Klebsiella and water bacteria like Pseudomonas indicates that individuals are at high-risk of infection due to poor hygiene conditions.

Ibekwe et $\mathrm{al}^{33}$, Maji et $\mathrm{al}^{34}$ and Indudharan et $\mathrm{al}^{35}$ who found negligible anaerobic isolates in their studies similar to our study. Fungal infections of the middle-ear are common as fungi thrive well in moist pus. Prakash et al ${ }^{31}$, Kumar et al ${ }^{27}$ and Osazuwa $\mathrm{H}$ el al29 found fungal isolates in $12.25 \%, 15 \%$ and $8.8 \%$ cases of CSOM respectively against $5 \%$ cases in our study.
When results of our study were compared with the findings of other researches, it was clear that microbial profile and of CSOM has been changing with due course of time. Geographical variation and difference inpatient population studied could be the possible factor for variability.

\section{CONCLUSION}

Chronic suppurative otitis media is one of the most common infectious diseases worldwide. CSOM like other chronic disease can limit an individual's employability and quality of life. Experts declare that when prevalence of CSOM is > $3 \%$, it must be targeted as a high-priority disease. In developing country like India, burden of infectious disease is relatively higher in the not so strong health care system. Hence, continuous and periodic evaluation of microbiological pattern and antibiotic sensitivity of isolates is necessary to decrease the potential risk of complications by early institution of appropriate treatment. Our study found higher incidence of CSOM in 31-40 years age group and in male patients of lower socioeconomic status with microbiological profile showing isolates of Pseudomonas aeruginosa 24\%, Klebsiella spp. 19\%, Staphylococcus spp. 15\%, Proteus spp. $12 \%$ and Escherichia coli $10 \%$. The disparity in findings from previous research can be attributed to the variation in climate, community environment, patient population, and indiscriminate use of antibiotics. Hence, our study emphasised the need of proper identification of microbiological profile of the cases of CSOM along with antibiotic sensitivity (although not analysed in the study) in order to facilitate early institution of proper treatment.

\section{REFERENCES}

[1] Smith AW, Hatcher J, Mackenzie IJ, et al. Randomized control trial of treatment of chronic suppurative otitis media in Kenyan school children. Lancet 1996;348(9035):1128-33.

[2] American Academy of Pediatrics Subcommittee on Management of Acute Otitis Media. Diagnosis and management of acute otitis media. Pediatrics 2004;113(5):1451-65.

[3] Jose A. Chronic suppurative otitis media: burden of illness and management options. Child and Adolescent Health and Development Prevention of Blindness and Deafness. World Health Organization, Geneva, Switzerland: 2004.

[4] Coticchia JM, Chen M, Sachdeva L, et al. New paradigms in the pathogenesis of otitis media in children. Front Pediatr 2013;1:52.

[5] Mittal R, Lisi CV, Gerring R, et al. Current concepts in the pathogenesis and treatment of chronic suppurative otitis media. J Med Microbiol 2015;64(10):1103-16.

[6] Acuin J. Chronic suppurative otitis media. BMJ Clin Evid 2007;2007:0507.

[7] Levi J, O'Reilly RC, Isaacson GC, et al. Chronic suppurative otitis media (CSOM): pathogenesis, clinical manifestations and diagnosis. 2016.

[8] Westerberg BD, Kozak FK, Thomas EE, et al. Is the healthy middle ear a normally sterile site? Otol Neurotol 2009;30(2):174-7.

[9] Hall-Stoodley L, Hu FZ, Gieseke A, et al. Direct detection of bacterial biofilms on the middle-ear 
mucosa of children with chronic otitis media. JAMA 2006;296(2):202-11.

[10] Baron S, Iglewski BH. Pseudomonas. In: Baron S. edr. Medical microbiology. $4^{\text {th }}$ edn. The University of Texas Medical Branch at Galveston, Galveston, TX: 1996.

[11] Ahn JH, Kim MN, Suk YA, et al. Preoperative, intraoperative and postoperative results of bacterial culture from patients with chronic suppurative otitis media. Otol Neurotol 2012;33(1):54-9.

[12] Albert RRA, Job A, Kuruvilla G, et al. Outcome of bacterial culture from mastoid granulations: is it relevant in chronic ear disease? J Laryngol Otol 2005;119(10):774-8.

[13] Byrd MS, Pang B, Hong W, et al. Direct evaluation of Pseudomonas aeruginosa biofilm mediators in a chronic Infection model. Infect Immun 2011;79(8):3087-95.

[14] Dohar JE, Hebda PA, Veeh R, et al. Mucosal biofilm formation on middle-ear mucosa in a nonhuman primate model of chronic suppurative otitis media. Laryngoscope 2005;115(8):1469-72.

[15] Chang J, Lee SH, Choi J, et al. Nasopharynx as a microbiologic reservoir in chronic suppurative otitis media: preliminary study. Clin Exp Otorhinolaryngol 2011;4(3):122-5.

[16] Yang JA, Kim JY, Yoon YK, et al. Epidemiological and genetic characterization of methicillin-resistant Staphylococcus aureus isolates from the ear discharge of outpatients with chronic otitis media. J Korean Med Sci 2008;23(5):762-6.

[17] Lee SK, Lee MS, Jung SY, et al. Antimicrobial resistance of Pseudomonas aeruginosa from otorrhea of chronic suppurative otitis media patients. Otolaryngol Head Neck Surg 2010;143(4):500-5.

[18] Berman S. Otitis media in developing countries. Pediatrics 1995;96(1 Pt 1):126-31.

[19] Chirwa M, Mulwafu W, Aswani JM, et al. Microbiology of chronic suppurative otitis media at Queen Elizabeth Central Hospital, Blantyre, Malawi: a cross-sectional descriptive study. Malawi Med J 2015;27(4):120-4.

[20] Melaku A, Lulseged S. Chronic otitis media in a children's hospital in Addis Ababa, Ethiopia. Ethiop Med J 1999;37(4):237-46.

[21] Van Hasselt P, van Kregten E. Treatment of chronic otitis media with ofloxacin in hydroxypropyl methylcellulose ear drops: a clinical/bacteriological study in a rural area of Malawi. Int J Paedtr Otorhinolaryngol 2002;63(1):49-56.

[22] Chowdhury MA, Alauddin M. Comparative study between tubotympanic and atticoantral types of chronic suppurative otitis media. Bangladesh Med Res Counc Bull 2002;28(1):36-44.
[23] Afolabi OA, Salaudeen AG, Ologe FE, et al. Pattern of bacterial isolates in the middle ear discharge of patients with chronic suppurative otitis media in a tertiary hospital in North Central Nigeria. Afr Health Sci 2012;12(3):362-7.

[24] Brook I, Frazier EH. Microbial dynamics of persistent purulent otitis media in children. J Pediatrics 1996;128(2):237-40.

[25] Ologe FE, Nwawolo CC. Prevalence of chronic suppurative otitis media (CSOM) among school children in a rural community in Nigeria. Niger Postgrad Med J 2002;9(2):63-6.

[26] Bluestone CD. WHO/CIBA foundation workshop. Report on prevention of hearing impairment for chronic otitis media. CIBA foundation, London, 1996: 14-7.

[27] Kumar H, Seth S. Bacterial and fungal study of 100 cases of chronic suppurative otitis media. J Clin Diagn Res 2011;5:1224-7.

[28] Shyamla R, Reddy PS. The study of bacteriological agents of chronic suppurative otitis media: aerobic culture and evaluation. J Microbiol Biotechnol Res 2012;2:152-62.

[29] Osazuwa F, Osazuwa E, Osime C, et al. Etiologic agents of otitis media in Benin city, Nigeria. N Am J Med Sci 2011;3(2):95-8.

[30] Mansoor T, Musani MA, Khalid G, et al. Pseudomonas aeruginosa in chronic suppurative otitis media: sensitivity spectrum against various antibiotics in Karachi. J Ayub Med Coll Abbottabad 2009;21(2):1203.

[31] Prakash R, Juyal D, Negi V, et al. Microbiology of chronic suppurative otitis media in a tertiary care setup of Uttarakhand State, India. $\mathrm{N} \mathrm{Am} \mathrm{J} \mathrm{Med}$ Sci 2013;5(4):282-7.

[32] Poorey VK, Iyer A. Study of bacterial flora in CSOM and its clinical significance. Indian J Otolaryngol Head Neck Surg 2002;54(2):91-5.

[33] Ibekwe AO, al Shareef Z, Benayam A. Anaerobes and fungi in chronic suppurative otitis media. Ann Otol Rhinol Laryngol 1997;106(8):649-52.

[34] Maji PK, Chatterjee TK, Chatterjee S, et al. The investigation of bacteriology of chronic suppurative otitis media in patients attending a tertiary care hospital with special emphasis on seasonal variation. Indian J Otolaryngol Head Neck Surg 2007;59(2):12831.

[35] Indudharan R, Haq JA, Aiyar S. Antibiotics in chronic suppurative otitis media: a bacteriologic study. Ann Otol Rhinol Laryngol 1999;108(5):440-5. 